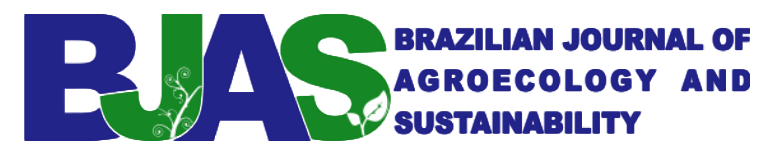

\title{
MÉTODO DA CLASSIFICAÇÃO CLIMÁTICA DE KÖPPEN E THORNTHWAITE APLICADO AO MUNICÍPIO DE BOM JESUS - PI, BRASIL
}

\section{KÖPPEN AND THORNTHWAITE CLIMATE CLASSIFICATION METHOD APPLIED TO THE MUNICIPALITY OF BOM JESUS - PI, BRAZIL}

\author{
Raimundo Mainar Medeiros ${ }^{1}$ \\ ${ }^{1}$ Universidade Federal de Campina Grande - PB, mainarmedeiros@gmail.com
}

DOI: https://doi.org/10.52719/bjas.v1i2.2648

\section{RESUMO}

O clima é o resumo dos elementos meteorológicos observados e registrados durante um longo período de tempo tendo estreita afinidade com a vegetação da área estudada. Tem-se como objetivo estudar e realizar a classificação climática pelo método de Köppen e Thornthwaite para o município de Bom Jesus- Piauí, gerando informações importantes para o planejamento e racionalização das suas diversas atividades produtivas e de políticas agropecuárias e de agronegócios, para as cooperativas e os agricultores em geral. Os dados meteorológicos foram obtidos do Instituto Nacional de Meteorologia, referentes à temperatura média mensal compensada do ar e pluviais precipitação pluviométrica mensal de período de 1960 a 2018. No modelo de Köppen o clima é do tipo Aw (clima tropical com estação seca de Inverno). Nas classificações climáticas de Thornthwaite, utilizando-se o Balanço Hídrico e os índices: hídrico, aridez e umidade têm-se os seguintes tipos climáticos em conformidades com o cenário pluviométrico, no cenário seco o clima é árido; no cenário regular o clima é semiárido; nos cenários chuvoso e médio os tipos de climas encontrados foram subúmido seco. Entre os meses de dezembro a julho a temperatura média tem representação de $64 \%$ da média anual e nos meses de agosto a novembro é de $36 \%$ da flutuabilidade térmica anual. Entre os meses de novembro a abril tem $89 \%$ de representação do índice pluvial anual e entre os meses de maio a outubro sua representação é de $10 \%$. Salienta-se que nos meses de julho e agosto não se observa ou registram índices pluviais.

Palavras-chave: Variações climáticas. planejamento agropecuário e agronegócios. irrigação.

\section{ABSTRACT}

Climate is the summary of meteorological elements observed and recorded over a long period of time having close affinity with the vegetation of the studied area. The objective is to study and perform the climate classification by the Köppen and Thornthwaite method for the municipality of Bom Jesus - Piauí, generating important information for the planning and 

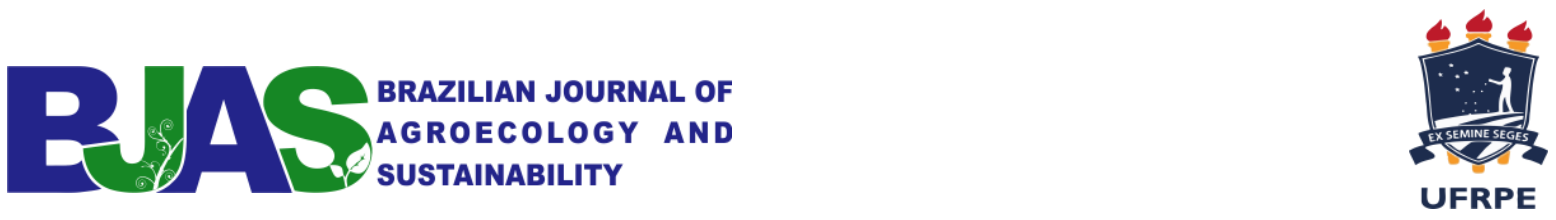

rationalization of its various productive activities and agricultural and agribusiness policies, for cooperatives. and farmers in general. Meteorological data were obtained from the National Institute of Meteorologyfor the monthly average compensated air temperature and rainfall. Mesnal rainfall from 1960 to 2018. In the Köppen model the climate is Aw (tropical climate with seasonal). winter drought). In the Thornthwaite climate classifications, using the Water Balance and the indices: water, aridity and humidity have the following climate types in accordance with the rainfall scenario, in the dry scenario the climate is arid; in the regular setting the climate is semiarid; In the rainy and medium scenarios the types of climates found were dry humid. From December to July the average temperature represents $64 \%$ of the annual average and from August to November is $36 \%$ of the annual thermal buoyancy. Between November and April it has $89 \%$ of the annual rainfall index and from May to October its representation is $10 \%$. It is noteworthy that in July and August no rain rates are observed or recorded.

Keywords: Climate variation, agricultural and agribusiness planning, irrigation

\section{INTRODUÇÃO}

As inúmeras variações espacialmente no clima são determinadas pelas diferentes combinações dos processos atmosféricos, os quais produzem correspondentemente, um grande número de tipos climáticos. Como ferramentas científicas fundamentais, as classificações climáticas possuem três objetivos que se inter-relacionam: ordenar grande quantidade de informações; facilitar a rápida recuperação e comunicação. Entre os métodos de classificações podemos citar as mais utilizadas classificações: Köppen, Thornthwaite, Martonne e a classificação de Sthraler.

Nóbrega (2010) afirmou que muitos dos sistemas de classificação climática podem ser falhos e imprecisos quanto a sua aplicabilidade, dependendo do conjunto de variáveis que são aplicadas para a definição das zonas climáticas e da forma com que estas variáveis são manipuladas. Todavia, a opção de um sistema de classificação climática dependerá, basicamente, das particularidades intrínsecas à área e ao objetivo do estudo (Rossato, 2011).

Os conhecimentos das condições climáticas de determinada região são necessárias para que se possam organizar estratégias, que visem o manejo adequado dos recursos naturais, planejando dessa forma, a busca por um desenvolvimento sustentável e a implementação das práticas agrícolas e suas produtividades viáveis e seguras ao meio ambiente, (Costa, Medeiros, Sousa, \& Oliveira, 2014). A estimativa do balanço hídrico (BH) e a classificação climática são ferramentas indispensáveis para a determinação da aptidão de áreas para culturas agrícolas e no planejamento de sistemas de irrigação (Passos, Zambrzycki, \& Pereira, 2017). 

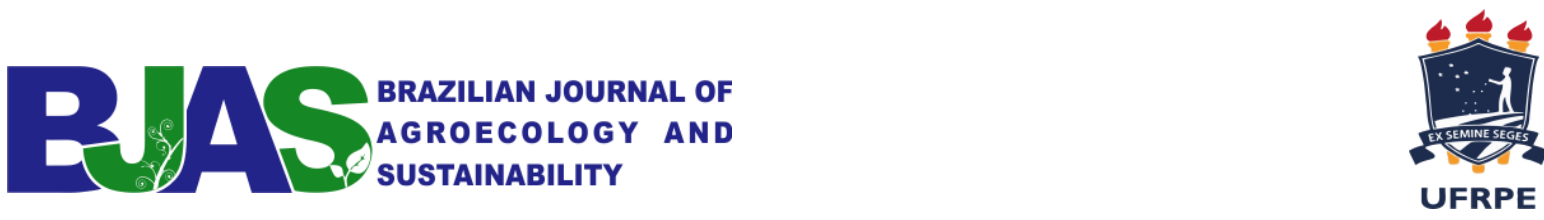

Medeiros, Holanda, Viana, \& Silva (2018) aplicaram o modelo da classificação de Köppen para o Estado de Pernambuco utilizando o método de interpolação Kriging. As classificações indicadas mostraram-se muito sensíveis à orografia municipal, aos índices pluviais e às oscilações de temperatura resultando em três tipos climáticos, tipo "AS" em 108 municípios, o tipo semiárido quente com precipitação de verão e inverno seco "BSh", foi registrado em 55 municípios e o tipo "Am” predominou em 20 municípios. O sistema de classificação climática Köppen é eficiente apenas para a macro escala e com baixa capacidade para separar os tipos de clima, levando em consideração a temperatura do ar, as chuvas e os elementos resultantes do balanço hídrico.

As condições climáticas e hidrológicas de uma determinada região são os principais parâmetros na estimativa das disponibilidades hídricas desse território. Estão nos estudos hidroclimatológicos as premissas básicas que nortearão o desenvolvimento dos trabalhos na definição do modelo de planejamento e gestão dos recursos hídricos a ser implementado (Medeiros, Sousa, \& Gomes, 2013).

A classificação climática de Köppen é baseada principalmente na quantidade e distribuição de precipitação e temperatura, anual e mensal. Os elementos de temperatura e precipitação constituem critério inicial para a divisão dos tipos de clima. Por ser uma classificação climática com mais de século, a classificação de Köppen passou por algumas adaptações de outros autores, como a de Setzer (1966), que simplificou a classificação criando uma chave classificatória.

Pereira, Angelocci, \& Sentelhas (2002) mostraram que os índices climáticos calculados pelo método do balanço hídrico, proveem de subsídios das disponibilidades hídricas ao longo do ano, através dos excedente hídrico, deficiência hídrica, retirada e reposição de água no solo. A partir desses valores anuais foram determinados os índices que promulgam a disponibilidade hídrica, de acordo com os índices climáticos de Thornthwaite (1955).

Tem-se como objetivo estudar e realizar a classificação climática pelo método de Köppen e Thornthwaite para o município de Bom Jesus, Piauí, referente ao período de 19602018, gerando informações para o planejamento e racionalização das suas diversas atividades produtivas e de políticas agropecuárias e de agronegócios, para as cooperativas e os agricultores em geral. 


\section{BRAZILIAN JOURNAL OF \\ AGROECOLOGY AND \\ SUSTAINABILITY}

\section{MATERIAL E MÉTODO}

\section{1 Área de estudo}

O município de Bom Jesus do Piauí localiza-se a uma latitude 0904'28"sul e a uma longitude 4421'31"oeste, com uma altitude média de 277 metros. Bom Jesus do Piauí está inserido na região dos cerrados piauienses e pertence à região do Vale do Rio Gurgueia. Possui uma área de $5.469 \mathrm{~km}^{2}$. Sua distância da capital Teresina é de $635 \mathrm{~km}$ em linha reta. O município possui um relevo bastante irregular, em grampe parte formada por chapadas de altitude e pequenos planaltos, $\mathrm{O}$ relevo do perímetro urbano é bastante acidentado, apresentado grande ladeiras e encostas, nos quais se situam as principais áreas de cultivo do milho e da soja, que são os produtos fontes da economia municipal., O principal recurso hídrico provém do Rio Gurgueia, importante afluente do Rio Parnaíba e principal rio da mesorregião do sudoeste piauiense. Segundo o censo 2010 (IBGE) sua população é de 22.629 habitantes (Figura 1).

Figura 1. Localização do município de Bom Jesus - PI. Fonte: Cordeiro, M.C. (2015).

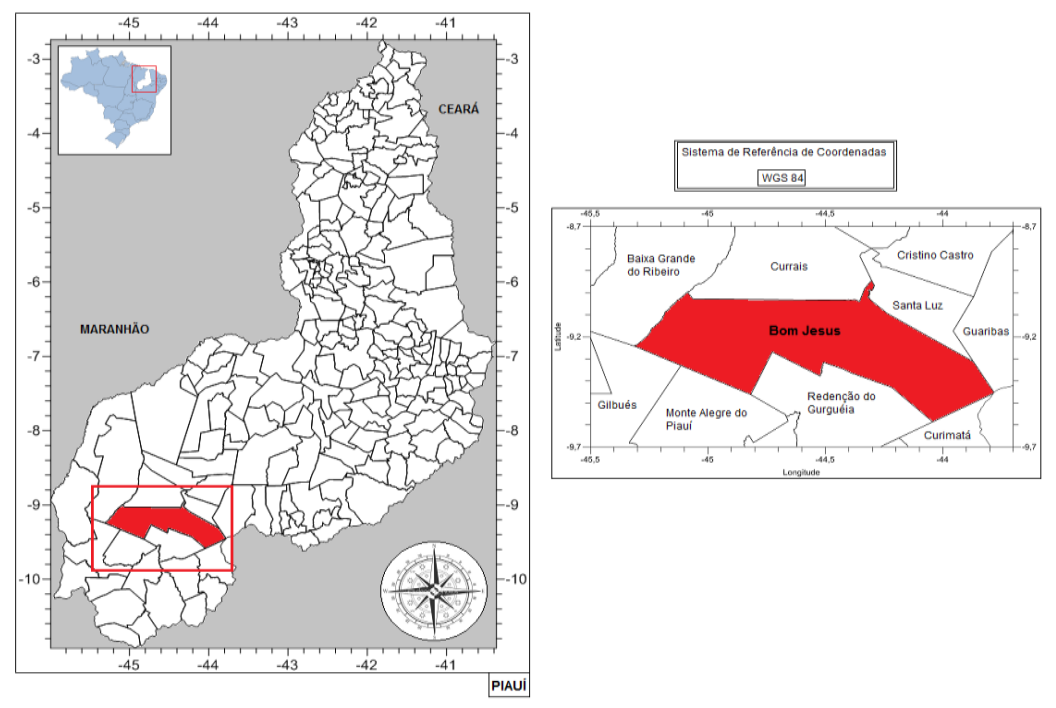

Dadas às informações climatológicas e dinâmicas da região Nordeste do Brasil (NEB), o município de Bom Jesus do Piauí tem seu clima controlado pela variabilidade espacial e temporal da Zona de Convergência do Atlântico Sul (ZCAS), e pelos vestígios das frentes frias (VFF), contribuição dos vórtices ciclônicos de altos níveis (VCAN), deste que seu centro esteja no oceano, as formações e intensificações das linhas de instabilidade (FILI) e dos aglomerados convectivos (AC), auxiliado pelos ventos alísios de sudeste (ASE), a convergência de umidade (CU) e a troca de calor sensível por latente e vice-versa, a contribuição da orografia e seus efeitos locais. (Medeiros, 2016). 

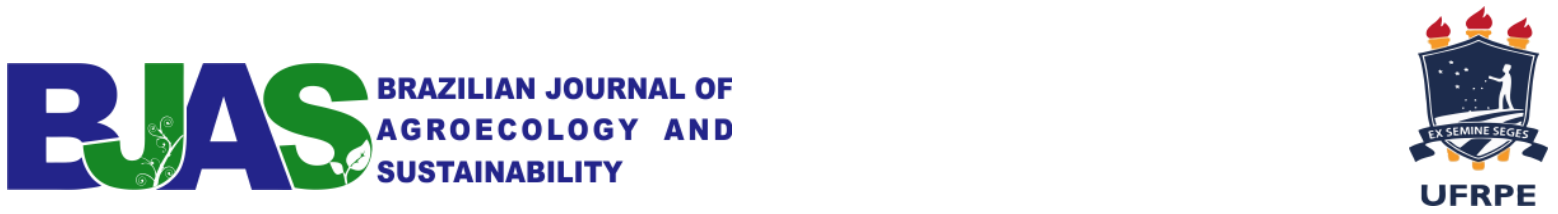

As contribuições dos efeitos locais, fatores que aumentam a cobertura de nuvens, a umidade relativa do ar e provocam chuvas de intensidades moderadas as fracas em quase todos os meses do ano, sendo o fenômeno La Niña o principal fator para ocorrência de chuvas acima da média histórica provocando inundações, alagamento, enchentes, enxurradas e desmoronamento (Figura 2).

Figura 2. Regimes e principais fatores provocadores de chuva no estado do Piauí. Fonte: autor (2015).

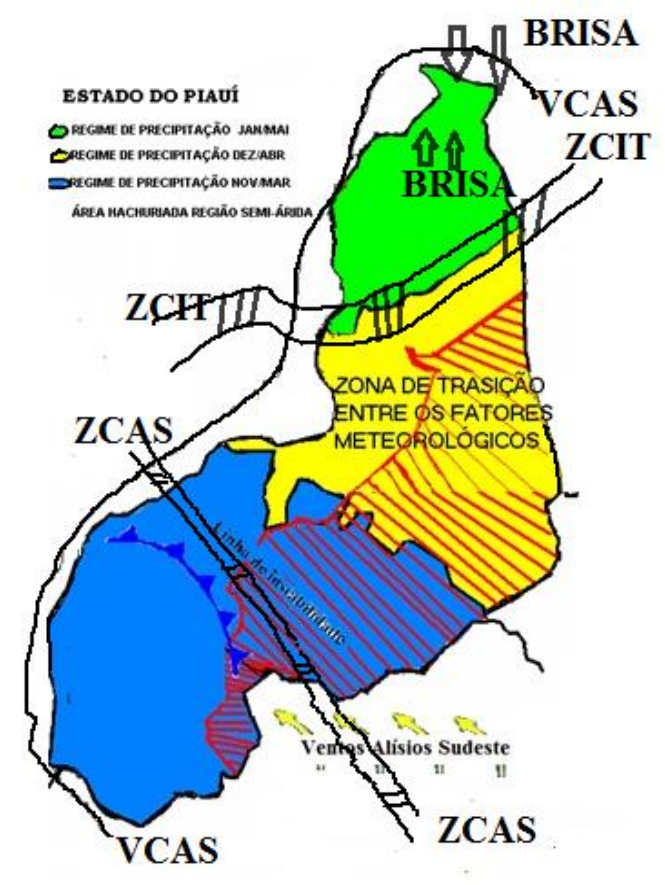

O estudo tem como principal importância fornecer subsídios aos agropecuaristas e aos agricultores familiares e aos tomadores de decisões governamentais para as possíveis alterações climáticas que possam vim ocorrerem na área municipal e seu entorno.

\subsection{Procedimentos metodológicos}

Os dados meteorológicos foram obtidos do Instituto Nacional de Meteorologia (INMET, 2019) referente aos dados mensais da temperatura média mensal compensada do ar e da precipitação pluviométrica no período de 1960 a 2018. Através de processamento realizado em planilhas eletrônicas dos dados de temperatura média mensal e suas respectivas precipitações média mensal (1960-2018) foram calculadas em nível municipal, os parâmetros estatísticos 

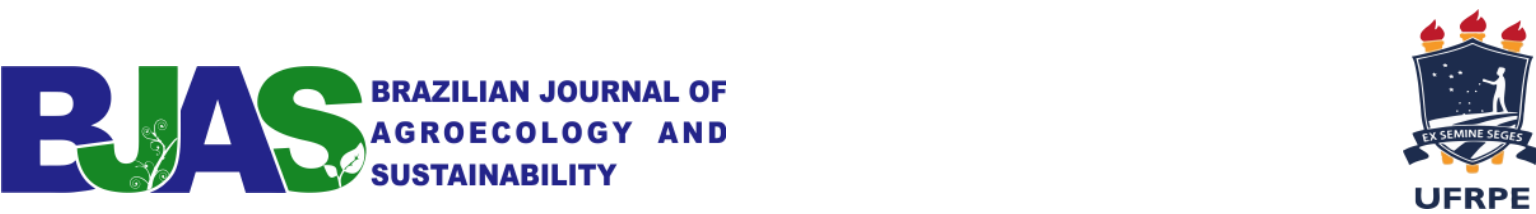

básicos como média, desvio padrão, coeficiente de variância, máximos e mínimos absolutos da série estudada. O cálculo do balanço hídrico $(\mathrm{BH})$ se deu através das formulações propostas por Thornthwaite (1948) e Thorthwaite, \& Mather (1955) aplicados a planilhas eletrônicas desenvolvidas por Medeiros (2016).

A utilização dos dados foi decorrida de análise no tocante à sua consistência, homogeneização e no preenchimento de falhas da sua série. Caso ocorram problemas nos equipamentos ou por impedimento do observador que resultem em dias sem observação ou mesmo intervalo de tempos maiores, os dados falhos foram preenchidos com os dados de três postos vizinhos, localizados o mais próximo possível, onde se aplicou da seguinte forma:

$$
P x=\frac{1}{3}\left(\frac{N x}{N a} P a+\frac{N x}{N b} P b+\frac{N x}{N c} P c\right)
$$

Em que:

Px é o valor de chuva que se deseja determinar;

Nx é a precipitação diária do posto $\mathrm{x}$;

NA, NB e NC são, respectivamente, as precipitações diárias observadas dos postos vizinhos A, $\mathrm{B}$ e C;

PA, PB e PC são, respectivamente, as precipitações observadas no instante que o posto $\mathrm{x}$ falhou.

Utilizaram-se quatro cenários pluviométricos na metodologia proposta por Thornthwaite (1948) e Thornthwaite \& Mather (1955) e conforme a aplicação da metodologia proposta por Varejão-Silva et al. (2001), usando a função de distribuição de probabilidade gama incompleta:

a) Cenário seco - constituído por anos nos quais o total de precipitação acumulada no trimestre mais chuvoso (TMC) é menor ou igual ao valor correspondente à probabilidade de $25 \%$;

b) Cenário chuvoso - constituído por anos nos quais o total de precipitação acumulada no TMC é maior ou igual ao valor correspondente à probabilidade de $75 \%$;

c) Cenário regular - constituído por aqueles anos não classificados nas duas categorias anteriores;

d) Os balanços hídricos, também, foram calculados segundo a metodologia clássica, usando-se toda a série de dados de chuva disponível, designado por "cenário médio". 

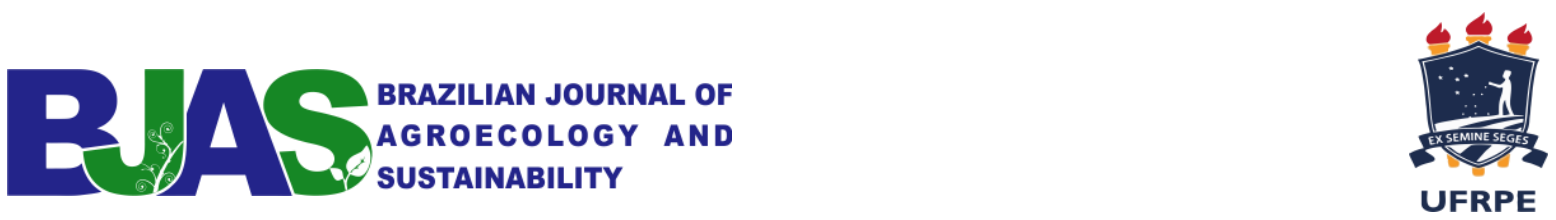

Em cada cenário pluviométrico, os cálculos dos balanços hídricos climatológicos e dos índices climáticos: hídrico, aridez e umidade foram processadas conforme Thornthwaite (1948) e Thornthwaite \& Mather (1955), assumindo-se a capacidade de água disponível do solo (CAD) igual a $100 \mathrm{~mm}$.

Varejão-Silva (2001) mostra que a função gama incompleta é um parâmetro que melhor detalha os índices pluviais de uma determinada localidade em suas distribuições de probabilidade.

\section{MÉTODO DA CLASSIFICAÇÃO DE KÖPPEN}

O sistema de classificação climática de köppen é extraordinário no âmbito da caracterização do clima de uma dada área e/ou região, auxiliando na compreensão das variações do clima no mundo (Ayoade, 2003). Tres. (2016) afirmaram que entre os sistemas de classificação mais utilizados no Brasil estão o de Köppen (1936), Thornthwaite (1948) e Holdridge (1966).

Baseia-se na classificação de várias regiões, tipos e variabilidades climáticas (Souza et al, 2013) indicado por três letras, que estão nos códigos, indicativos dos grupo (Tabela 1), do indicador de tipo (Tabela 2) e indicador do subtipo (Tabela 3).

Tabela 1: Caracterização do indicador de grupo climático

\begin{tabular}{ccl}
\hline Código & Tipo de clima & \multicolumn{1}{c}{ Descrição } \\
\hline \multirow{2}{*}{ A } & Tropical & $\begin{array}{l}\text { Climas megatérmicos: Temperatura média do mês mais frio } \\
\text { maior que } 18^{\circ} \mathrm{C} ; \text { Estação invernosa ausente; Precipitação } \\
\end{array}$ \\
& anual superior a Evapotranspiração anual. \\
B & Árido & Climas secos (Precipitação anual menor que $500 \mathrm{~mm}$ ); \\
& & Evapotranspiração anual superior a Precipitação anual; \\
& & Inexistência de cursos d'água permanentes.
\end{tabular}


C Temperado Climas mesotérmicos; Temperatura média do mês mais frio entre -3 e $18^{\circ} \mathrm{C}$ (considerando a mínima média); Temperatura média do mês mais quente maior que $10^{\circ} \mathrm{C}$; Verão e inverno bem definidas.

D Continental Climas microtérmicos; Temperatura média do ar do mês mais frio menor ou igual a $3^{\circ} \mathrm{C}$; Temperatura média do mês mais quente maior que $10^{\circ} \mathrm{C}$; Verão e inverno bem definido.

E Glacial Climas polares e de alta montanha; Temperatura média mês mais quente maior que $10^{\circ} \mathrm{C}$; Verão pouco definido ou inexistente.

Os indicadores de tipo climático estão representados na Tabela 2.

Tabela 2: Caracterização do indicador de tipo climático.

\begin{tabular}{|c|c|c|}
\hline Código & Descrição & Grupo \\
\hline$S$ & $\begin{array}{l}\text { Clima das estepes; Precipitação anual média } \\
\text { entre } 380 \text { e } 760 \mathrm{~mm} .\end{array}$ & B \\
\hline $\mathrm{W}$ & $\begin{array}{l}\text { Clima desértico; Precipitação anual média < } \\
250 \mathrm{~mm}\end{array}$ & B \\
\hline $\mathrm{F}$ & $\begin{array}{l}\text { Clima úmido; Ocorrência de precipitação em } \\
\text { todos os meses do ano; Inexistência de estação } \\
\text { seca definida; Precipitação do mês mais seco > } \\
60 \mathrm{~mm} \text {. }\end{array}$ & A-B-C \\
\hline $\mathrm{W}$ & Chuvas de verão. & $\mathrm{A}-\mathrm{B}-\mathrm{C}$ \\
\hline$S$ & Chuvas de inverno & A-B-C \\
\hline $\mathrm{W}^{\prime}$ & Chuvas de verão-outono & $\mathrm{A}-\mathrm{B}-\mathrm{C}$ \\
\hline$S^{\prime}$ & Chuvas de inverno-outono. & A-B-C \\
\hline
\end{tabular}


M Clima de monção; Precipitação anual média

$>1500$ mm e Precipitação do mês mais seco <

$60 \mathrm{~mm}$.

T Temperatura média do ar no mês mais quente entre 0 e $10^{\circ} \mathrm{C}$

F Temperatura média do mês mais quente $<0{ }^{\circ} \mathrm{C}$. $\mathrm{E}$

M Precipitação abundante (inverno pouco rigoroso).

Os indicadores do subtipo climático estão representados na Tabela 3.

Tabela 3: Caracterização do indicador de subtipo climático

\begin{tabular}{|c|c|c|}
\hline Código & Descrição & Grupo \\
\hline a: Verão quente & $\begin{array}{l}\text { Temperatura média do ar no mês mais quente maior que } \\
22^{\circ} \mathrm{C} \text {. }\end{array}$ & C-D \\
\hline b: verão temperado & $\begin{array}{l}\text { Temperatura média do ar no mês mais quente menor que } \\
22^{\circ} \mathrm{C} \text {; Temperatura média do ar nos } 4 \text { meses mais quentes } \\
\text { maior que } 10^{\circ} \mathrm{C}\end{array}$ & C-D \\
\hline $\begin{array}{l}\text { c: verão curto e } \\
\quad \text { fresco }\end{array}$ & $\begin{array}{l}\text { Temperatura média do ar no mês mais quente menor que } \\
22^{\circ} \mathrm{C} \text {; - Temperatura médias do ar maior que } 10^{\circ} \mathrm{C} \\
\text { durante menos de } 4 \text { meses; Temperatura média do ar no } \\
\text { mês mais frio maior que }-38^{\circ} \mathrm{C} \text {. }\end{array}$ & C-D \\
\hline $\begin{array}{l}\mathrm{d} \text { : inverno muito } \\
\quad \text { frio }\end{array}$ & $\begin{array}{l}\text { Temperatura média do ar no mês mais frio menor que - } \\
38^{\circ} \mathrm{C} \text {. }\end{array}$ & D \\
\hline h: seco e quente & $\begin{array}{l}\text { Temperatura média anual do ar maior que } 18^{\circ} \mathrm{C} \text {; Deserto } \\
\text { ou semi deserto quente (Temperatura anual média do ar } \\
\text { igual ou superior a } 18^{\circ} \mathrm{C} \text { ). }\end{array}$ & B \\
\hline $\mathrm{k}$ : seco e frio & $\begin{array}{l}\text { Temperatura média anual do ar menor que } 18^{\circ} \mathrm{C} \text {; Deserto } \\
\text { ou semideserto frio (Temperatura anual média do ar igual } \\
\text { ou inferior a } 18^{\circ} \mathrm{C} \text { ). }\end{array}$ & B \\
\hline
\end{tabular}




\subsection{MÉTODO DA CLASSIFICAÇÃO DE THORNTHWAITE}

O método proposto por Thornthwaite (1948) utiliza dados do excesso e déficit hídrico anual, derivada do balanço hídrico. Determinou para cada período o índice de hídrico (Ih), que é a relação entre excesso de água pela evapotranspiração potencial expressa em porcentagem (Silva, Moura, \& Klar, 2014), dado pela equação.

\section{$\mathrm{Ih}=(\mathrm{EXC} / \mathrm{ETP}) * 100$}

A seguir determinou-se o índice de aridez (Ia), que expressa a déficit hídrica em porcentagem em relação à evapotranspiração potencial, variando de 0 a 100. Segundo Miranda (2008) quando o índice de aridez atinge valor 0 , isso indica que não há déficit hídrico, porém quando o Ia atinge o valor de 100, isso quer dizer que a déficit é igual à evapotranspiração potencial, estando em condições de extrema aridez. O índice de aridez é determinado pela equação.

\section{$\mathrm{Ia}=(\mathrm{DEF} / \mathrm{ETP}) * 100$}

Finalizado os cálculos do Ih e do Ia estimou-se o índice umidade (Iu) que relaciona os dois índices acima e é responsável por determinar o tipo climático local (Cunha \& Martins, 2009) obtendo o primeiro indicativo da fórmula climática representado por uma letra alfabética maiúscula, com ou sem um algarismo subscrito (Tabela 4). O índice umidade abrange período úmido a seco durante todo o ano em sua condição climática (Thorthwaite, 1948). Segundo esse mesmo autor, se ocorrer uma situação em que a deficiência hídrica não ultrapassa $60 \%$ dos excedentes hídricos no período úmido, então não ocorrerá uma seca, ou seja, o índice umidade terá que ser igual à zero $(\mathrm{Iu}=0)$. Este índice foi posteriormente utilizado para a classificação climática do local estudado, equação seguinte.

\section{Iu=Ih-0,6*Ia}

Miranda (2008) mostra que a segunda letra da fórmula, que pode ser maiúscula ou minúscula com ou sem subscrito (Tabela 5), com o subtipo climático diferenciando o período de umidade e aridez que correr durante o ano em função da distribuição interanual da pluviosidade.

Para determinação da terceira letra da fórmula climática é necessário o índice de eficiência térmica. Este índice corresponde ao valor numérico da evapotranspiração potencial, sendo a função direta da temperatura e do fotoperíodo. É apresentada por uma letra maiúscula com apóstrofo e, com ou sem um algoritmo subscrito (Tabela 6).

Na determinação da quarta letra da fórmula leva-se em consideração a porcentagem da evapotranspiração potencial que ocorrer nos meses do verão, fornecendo o subtipo climático 
(Tabela 7). É indicada por uma letra minúscula com apostrofo e, com ou sem um algarismo subscrito.

Tabela 4: Chave inicial da classificação climática segundo Thornthwaite, baseado nos índices de umidade.

\begin{tabular}{cc}
\hline Tipos Climáticos & Índice de Umidade (Iu) \\
\hline A - Super-úmido & $100 \leq \mathrm{Iu}$ \\
B $_{4}$ - Úmido & $80 \leq \mathrm{Iu}<100$ \\
$\mathrm{~B}_{3}$ - Úmido & $60 \leq \mathrm{Iu}<80$ \\
$\mathrm{~B}_{2}$ - Úmido & $40 \leq \mathrm{Iu}<60$ \\
$\mathrm{~B}_{1}$ - Úmido & $20 \leq \mathrm{Iu}<40$ \\
$\mathrm{C}_{2}$ - Subúmido & $00 \leq \mathrm{Iu}<20$ \\
$\mathrm{C}_{1}$ - Subúmido seco & $-33,33 \leq \mathrm{Iu}<0,0$ \\
D - Semiárido & $-66,7 \leq \mathrm{Iu}<-33,33$ \\
E - Árido & $-100 \leq \mathrm{Iu}<-66,7$ \\
\hline
\end{tabular}

Fonte: Ometto (1981).

Tabela 5: Segundo chave da classificação climática segundo Thornthwaite, baseados nos índices de aridez e umidade.

\begin{tabular}{|c|c|c|c|}
\hline $\begin{array}{c}\text { Climas úmidos } \\
(\mathrm{A}, \mathrm{B} 4, \mathrm{B3}, \mathrm{B} 2, \mathrm{~B} 1 \text { e C2) }\end{array}$ & $\begin{array}{l}\text { Índice de Aridez } \\
\text { (Ia) }\end{array}$ & $\begin{array}{l}\text { Climas secos } \\
(\text { C1, D e E) }\end{array}$ & $\begin{array}{l}\text { Índice de umidade } \\
\text { (Iu) }\end{array}$ \\
\hline $\begin{array}{c}\mathbf{r}-\text { pequena ou nenhuma } \\
\text { deficiência de água }\end{array}$ & $0-16,7$ & $\begin{array}{l}\text { pequeno ou nenhum } \\
\text { excesso de água }\end{array}$ & $0-10$ \\
\hline $\begin{array}{l}\text { - moderada deficiência no } \\
\text { verão }\end{array}$ & $16,7-33,33$ & $\begin{array}{l}\text { moderado excesso de } \\
\text { inverno }\end{array}$ & $10-20$ \\
\hline $\begin{array}{c}\mathbf{w}-\text { moderada deficiência } \\
\text { no inverno }\end{array}$ & $16,7-33,33$ & $\begin{array}{l}\text { - moderado excesso de } \\
\text { verão }\end{array}$ & $10-20$ \\
\hline $\begin{array}{l}\text { - grande deficiência } \\
\text { no verão }\end{array}$ & $>33,33$ & $\begin{array}{l}\text { - largo excesso de } \\
\text { inverno }\end{array}$ & 20 \\
\hline $\begin{array}{l}\text { - grande deficiência no } \\
\text { inverno }\end{array}$ & $>33,33$ & largo excesso de verão & 20 \\
\hline
\end{tabular}


Tabela 6: Terceira chave de classificação climática segundo Thornthwaite, baseado no índice térmico (ETo anual).

\begin{tabular}{|c|c|}
\hline Tipo climático & Índice térmico (EToanual) \\
\hline $\mathrm{A}^{\prime}$ - megatérmico & $\geq 1.140$ \\
\hline $\mathrm{B}_{4}{ }_{4}$ - mesotérmico & $997-1.140$ \\
\hline $\mathrm{B}_{3}{ }_{3}-$ mesotérmico & $855-997$ \\
\hline $\mathrm{B}_{2}{ }_{2}$ - mesotérmico & $712-855$ \\
\hline $\mathrm{B}_{1}{ }_{1}$ - mesotérmico & $570-712$ \\
\hline $\mathrm{C}_{2}{ }_{2}-$ microtérmico & $427-570$ \\
\hline $\mathrm{C}^{\prime}{ }_{1}$ - microtérmico & $285-427$ \\
\hline$D^{\prime}-$ tundra & $142-285$ \\
\hline E' - gelo perpétuo & $<142$ \\
\hline
\end{tabular}

Fonte: Ometto (1981).

Na Tabela 7 tem-se a Quarta chave de classificação climática segundo Thornthwaite, baseado na relação entre a ETP de verão (ETPv) e anual (ETP). Com bases nos valores das ETPs verifica-se a faixa na tabela com o subtipo climático.

Tabela 7: Quarta chave de classificação climática segundo Thornthwaite, baseado na relação entre a ETP de verão (ETPv) e anual (ETP).

\begin{tabular}{cc}
\hline Subtipo climático & Concentração da ETP no verão (\%) \\
\hline a' $^{\prime}$ & $<48 \%$ \\
b'4 $^{\prime}$ & $48-51,9$ \\
b'3 & $51,9-5673$ \\
b'2 & $56,3-61,6$ \\
b'1 & $61,6-68,0$ \\
c'2 & $68,0-76,3$ \\
c'1 & $76,3-88,00$ \\
d' & $>88,00$
\end{tabular}

Fonte: Ometto (1981). 


\section{RESULTADOS E DISCUSSÕES}

Na Tabela 8 têm-se os resultados do Balanço Hídrico para o município de Bom Jesus do Piauí, segundo a metodologia proposta por Thornthwaite \& Mather (1955), para o período de 1960 a 2018. Com temperatura média anual de $27,3^{\circ} \mathrm{C}$ e suas flutuações mensais oscilando entre $26,3^{\circ} \mathrm{C}$ (janeiro) a $28,8^{\circ} \mathrm{C}$ (setembro). Os índices pluviais oscilam entre $1,5 \mathrm{~mm}$ no mês de agosto a 174,1 mm em janeiro com precipitação total anual de 984,8 mm. Evapotranspirou $45,7 \%$ acima do valor da precipitação, a evaporação igualou-se aos índices pluviais, com deficiência hídrica de $827,9 \mathrm{~mm}$ sem ocorrência de excedentes hídricos durantes os meses.

Tabela 8: Resultado do Balanço Hídrico para o município de Bom Jesus do Piauí, segundo a metodologia proposta por Thornthwaite \& Mather, (1955), para o período de 1960-2018.

\begin{tabular}{|c|c|c|c|c|c|c|}
\hline Meses & $\begin{array}{l}\text { Temp } \\
\left({ }^{\circ} \mathrm{C}\right)\end{array}$ & $\begin{array}{l}\text { Prec } \\
(\mathrm{mm})\end{array}$ & $\begin{array}{l}\text { ETP } \\
(\mathrm{mm})\end{array}$ & $\begin{array}{l}\text { EVR } \\
(\mathrm{mm})\end{array}$ & $\begin{array}{l}\mathrm{EXC} \\
(\mathrm{mm})\end{array}$ & $\begin{array}{l}\text { DEF } \\
(\mathrm{mm})\end{array}$ \\
\hline Jan & 26,3 & 173,3 & 133,0 & 133,0 & 0,0 & 0,0 \\
\hline $\mathrm{Fev}$ & 26,8 & 159,2 & 132,2 & 132,2 & 0,0 & 0,0 \\
\hline Mar & 26,5 & 166,4 & 139,0 & 139,0 & 0,0 & 0,0 \\
\hline Abr & 26,7 & 101,2 & 134,8 & 128,4 & 6,4 & 0,0 \\
\hline Mai & 26,9 & 22,6 & 140,2 & 69,4 & 70,8 & 0,0 \\
\hline Jun & 26,9 & 3,3 & 135,3 & 18,8 & 116,5 & 0,0 \\
\hline Jul & 27,1 & 2,3 & 142,1 & 6,7 & 135,4 & 0,0 \\
\hline Ago & 27,9 & 1,6 & 161,9 & 2,7 & 159,2 & 0,0 \\
\hline Set & 28,8 & 10,6 & 183,0 & 9,2 & 173,8 & 0,0 \\
\hline Out & 28,7 & 68,7 & 190,4 & 70,0 & 120,4 & 0,0 \\
\hline Nov & 27,7 & 124,5 & 161,8 & 127,0 & 34,8 & 0,0 \\
\hline Dez & 27,2 & 144,7 & 158,8 & 148,3 & 10,5 & 0,0 \\
\hline
\end{tabular}




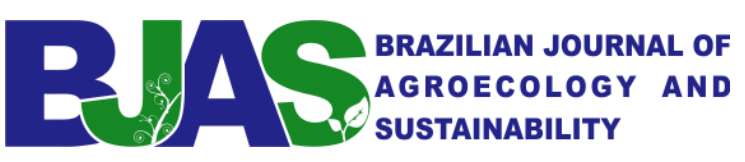

Anual

27,3

984,8

1812,7

984,8

827,9

0,0

Legenda: Temp = Temperatura média do ar; Prec = Precipitação; ETP = Evapotranspiração; EVR $=$ Evaporação; EXC = Excedente hídrico e DEF = Deficiência hídrica. Fonte: Autor (2019).

Estas oscilações se devem ao potencial energético da região, de acordo com a estação do ano, como explicam Medeiros, Francisco, Santos, Silva, \& Bandeira (2015) ao afirmarem que as maiores médias térmicas de temperatura do ar na superfície ocorrem durante o verão, e as menores, durante o inverno, mesmo as que se encontram em baixas latitudes.

Na Figura 3 observam-se o gráfico do Balanço hídrico climatológico, segundo Thornthwaite \& Mather (1955) do município de Bom Jesus do Piauí, baseado em dados termopluviométricos médios do período 1960-2018. As deficiências hídricas (vermelho) foram registradas entre os meses de abril a dezembro. A reposição de água no solo ocorreu entre os meses de janeiro a março. A retirada de água no solo registrou-se entre abril a julho, não ocorreram excedentes hídricos. Os índices pluviais excederam a ETP e EVR nos meses de janeiro a março; a EVR igualou-se aos índices pluviais de julho a dezembro.

Figura 3 - Gráfico do Balanço hídrico climatológico, segundo Thornthwaite \& Mather (1955) do município de Bom Jesus do Piauí, baseado em dados termopluviométricos médios do período 1960-2018.

Figura 3 - Gráfico do Balanço hídrico climatológico

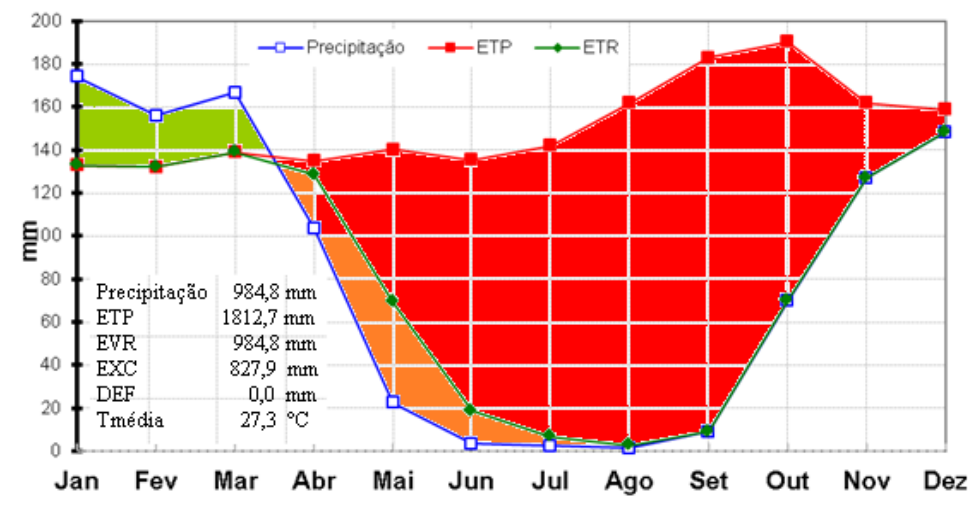

Fonte: Autor (2019).

A classificação de Köppen baseia-se fundamentalmente na temperatura, na precipitação e na distribuição de valores de temperatura e precipitação durante as estações do ano.

A distribuição mensal dos índices pluviais e seus respectivos percentuais em relação à média anual do período 1960-2018 em Bom Jesus do Piauí está representada na gráfico 1. Entre os meses de novembro a abril tem $89 \%$ de representação do índice pluvial anual e entre os 

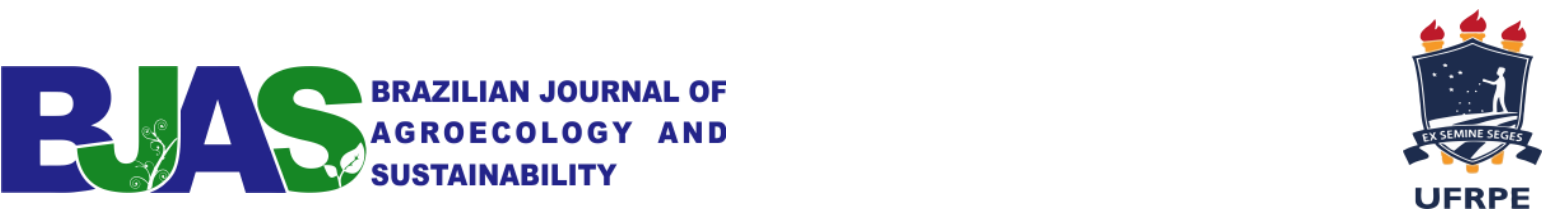

meses de maio a outubro tem-se $10 \%$ do índice pluvial anual. Salienta-se que nos meses de julho e agosto não se observa ou registram índices pluviais.

Gráfico 1 - Distribuição mensal dos índices pluviais e seus respectivos percentuais em relação (ao valor médio do total anual) do período 1960-2018 em Bom Jesus do Piauí.

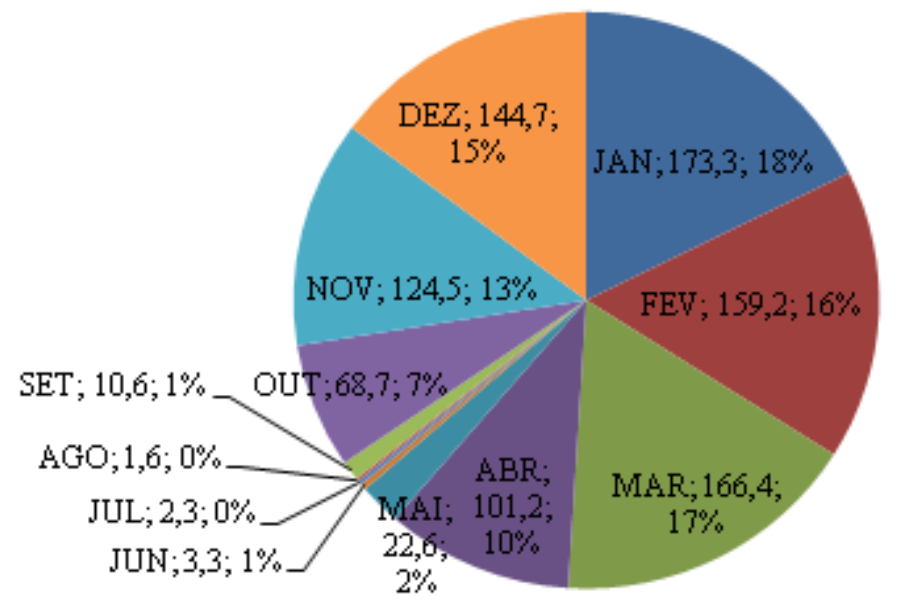

Fonte: Medeiros (2019).

No gráfico 2 observam-se as flutuações das distribuições mensais da temperatura média do ar e seus respectivos percentuais em relação à média anual do período 1960-2018 em Bom Jesus do Piauí. Nos meses de dezembro a julho a temperatura média de $64 \%$ de representação da media na sua flutuabilidade térmica. Nos meses de agosto a novembro a flutuabilidade térmica é de $36 \%$ do valor da média anual. Tais oscilações estão em conformidade com Medeiros (2016) e Marengo et al. (2004; 2011). Estes estudos vêm a corroborar com os resultados encontrados neste artigo.

Gráfico 2 - Distribuição mensal da temperatura média do ar e seus respectivos percentuais em relação à média anual do período 1960-2018 em Bom Jesus do Piauí.

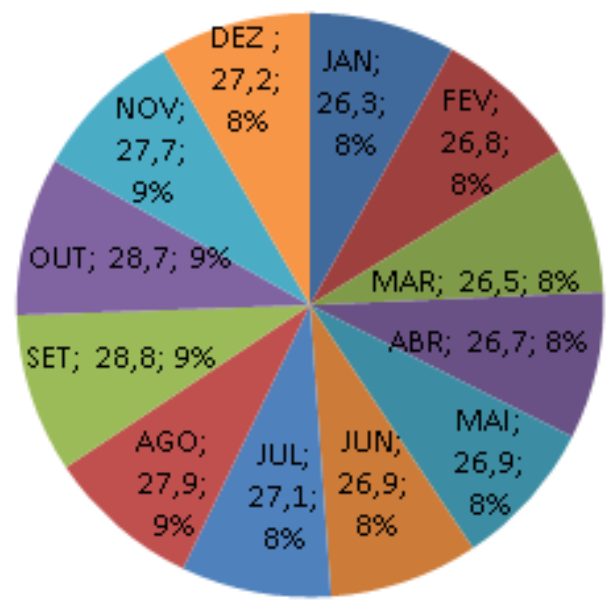

Fonte: Autor (2019). 
Na Tabela 9 destacam-se os valores dos índices climáticos do município de Bom Jesus do Piauí, baseado em dados termopluviométricos médios do período 1960-2018, estes índices foram gerados pelo cálculo do balanço hídrico climatológico do referido período em estudo.

Tabela 9 - Índices climáticos do município de Bom Jesus do Piauí, baseado em dados termopluviométricos médios do período 1960-2018.

\section{Índices climáticos}

Índice umidade (\%) Índice de aridez (\%) Índice hídrico (\%)
45,67
0,46
$-0,27$

Fonte: Tecla Ticiane

Tabela 10 - Classificações climáticas segundo Thornthwaite \& Mather, utilizando-se o

Balanço Hídrico e os índices: hídrico, aridez e umidade.

TIPOS CLIMÁTICOS PREDOMINANTES

\begin{tabular}{ccccc}
\hline Cenário & Seco & Regular & Chuvoso & Médio \\
Pluviométrico & & & & \\
Classificação & Árido & Semiárido & Subúmido & Subúmido \\
& & & Seco & Seco \\
\hline
\end{tabular}

Fonte: Autor

A classificação de Köppen baseia-se fundamentalmente na temperatura, na precipitação e na distribuição de valores de temperatura e precipitação durante as estações do ano. De acordo com a classificação climática pelo método de Köppen (1928, 1931) Bom Jesus do Piauí tem o clima Aw (clima tropical com estação seca de Inverno) concordando com os estudos realizados Alvares et al. (2013.

\section{CONCLUSÕES}

Segundo o modelo da classificação de Köppen o clima e do tipo Aw (clima tropical com estação seca de Inverno). 

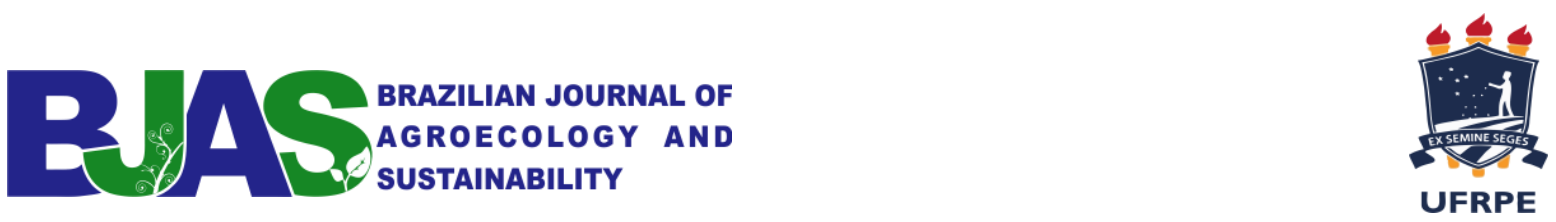

Nas classificações climáticas segundo Thornthwaite e Mather (1955), utilizando-se o Balanço Hídrico e os índices hídricos, aridez e umidade têm-se os seguintes tipos climáticos em conformidades com o cenário pluviométrico: no cenário seco o clima é árido; para o cenário regular o clima é do tipo semiárido; nos cenários chuvoso e médio os tipos de climas encontrados foram subúmido seco.

No município de Bom Jesus do Piauí entre os meses de dezembro a julho a temperatura média tem representação de $64 \%$ da média anual na sua flutuabilidade térmica. Nos meses de agosto a novembro a flutuabilidade térmica é de $36 \%$ do valor da média anual.

Entre os meses de novembro a abril tem $89 \%$ de representação do índice pluvial anual e entre os meses de maio a outubro tem-se $10 \%$ do índice pluvial anual. Salienta-se que nos meses de julho e agosto não se observa ou registram índices pluviais.

$\mathrm{O}$ artigo fornece subsídios para elaborações das atividades produtivas e de políticas agropecuárias e de agronegócios para as cooperativas e os agricultores em geral. Mostrando suas flutuações pluviais e térmicas aos tomadores de decisões e repassadas a população e ao governo no planejamento das referidas atividades.

\section{REFERENCIAS}

Alvares, C. A., Stape, J. L., Sentelhas, P. C., de Moraes Gonçalves, J. L. \& Sparovek, G. (2013). Köppen's climate classification map for Brazil. Meteorologische Zeitschrift, Berlin, 22(6), 711-728.

Alvares, C. A., Stape, J. L., Sentelhas, P. C., \& de Moraes Gonçalves, J. L. (2013). Modeling monthly mean air temperature for Brazil. Theoretical and Applied Climatology, 113(3-4), 407-427.

Ayoade, J. O. (2003). Introdução à climatologia para os trópicos (9a ed.). Rio de Janeiro: Bertrand Brasil.

Costa Neto, F. A., Medeiros, R. M., Sousa, E. P., \& Oliveira, R. C. S. (2014, agosto). Balanço hídrico como planejamento para a cidade de Olivedos - PB. Congresso Técnico Científico da Engenharia e da Agronomia, CONTECC, Teresina, PI, Brasil.

Cunha, A. R., \& Martins, D. (2009, janeiro/março). Classificação climática para os municípios de Botucatu e São Manuel, SP. Irriga, Botucatu, 14(1), 1-11. DOI: http://dx.doi.org/10.1580 09/irriga.2009v14n1p01

Holdridge, L. R. (1966). The life zone system. Adansonia, 6(2), 199-203.

Instituo Nacional de Meteorologia. (2019). Normais climatológicas. Brasília - DF: INMET.

Köppen, W. (1931). Grundriss der Klimakunde: outline of climate science (p. 388). Berlin: Walter de Gruyter. 

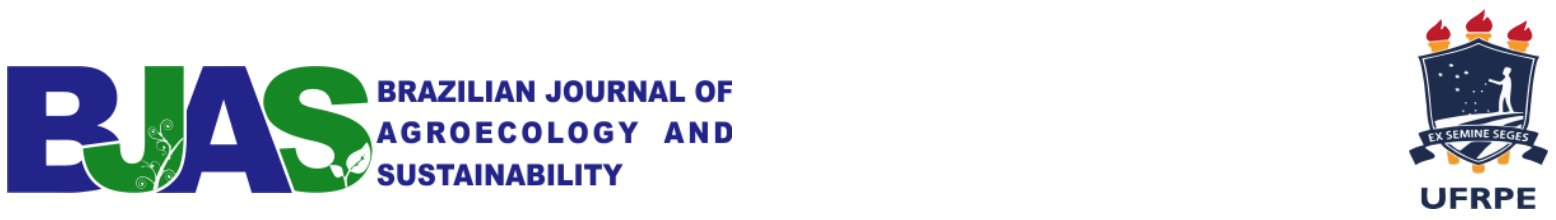

Köppen, W., \& Geiger, R. (1928). Klimate der Erde. Gotha: Verlag Justus Perthes.

Koppen, W. (1936). Das geographische system der klimat. Handbuch der klimatologie, 46.

Marengo, J. A. (2004). Interdecadal variability and trends of rainfall across the Amazon basin. Theoretical and applied climatology, 78(1-3), 79-96.

Marengo, J. A., Alves, L. M., Beserra, E. A., \& Lacerda, F. F. (2011). Variabilidade e mudanças climáticas no semiárido brasileiro. Recursos hídricos em regiões áridas e semiáridas, 1 .

Medeiros, R. M., Holanda, R. M., Viana, M. A., \& Silva, V. P. (2018). Climate classification in Köppen model for the state of Pernambuco - Brazil. Revista de Geografia, Recife, 35(3), 219 234.

Recuperado

de https://periodicos.ufpe.br/revistas/revistageografia/search/search?simpleQuery=medeiros \&searchField=authors

Medeiros, R. M. (2016). Balanço hídrico em planilhas eletrônicas segundo o método de Thornthwaite.

Medeiros, R. M., Francisco, P. R. M., Santos, D., Silva, L. L. da, \& Bandeira, M. M. (2015). Variabilidade da temperatura média do ar no Estado da Paraíba - Brasil. Revista Brasileira de Geografia Física, 8(1), 128-135. Recuperado de https://periodicos.ufpe.br/revistas/rbgfe/article/view/233433

Medeiros, R. M., Sousa, F. A. S., \& Gomes Filho, M. F. (2013). Análise Climatológica, Classificação Climática e Variabilidade do Balanço Hídrico Climatológico na Bacia do Rio Uruçuí Preto, PI. Revista Brasileira de Geografia Física, Rio de Janeiro, 6(4), 652-664.

Miranda, E. E. (2005). Brasil em relevo. Campinas: Embrapa Monitoramento por Satélite. Recuperado de http://www.relevobr.cnpm.embrapa.br.

Nóbrega, R. S. (2010). Um pensamento crítico sobre classificações climáticas: de Köppen até Strahler. Revista Brasileira de Geografia Física, Recife, 3, 18-22.

Passos, M. L. V., Zambrzycki, G. C., \& Pereira, R. S. (2017). Balanço hídrico climatológico e classificação climática para o Município de Balsas - MA. Revista Scientia Agraria, 18(1), 83-89.

Pereira, A. R., Angelocci, L. R., \& Sentelhas, P. C. (2002). Agrometeorologia: fundamentos e aplicações práticas. Guaíba: Agropecuária.

Rossato, M. S. (2011). Os climas do Rio Grande do Sul: variabilidade, tendências e tipologia. Tese doutorado, Universidade Federal do Rio Grande do Sul, Porto Alegre.

Silva, A. O., Moura, G. B. A., \& Klar, A. V. (2014). Classificação climática de Thornthwaite e sua aplicabilidade agroclimatológica nos diferentes regimes de precipitação em Pernambuco. Irriga, Botucatu, 19(1), 46 - 60. 

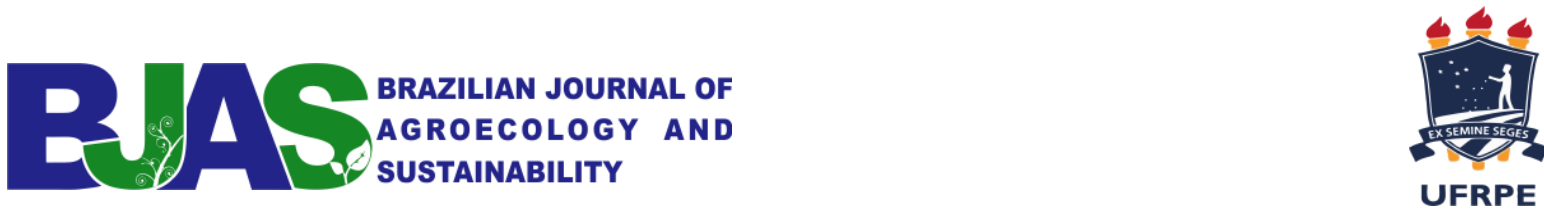

Souza, A. P. de, Mota, L. L. da, Zamadei, T., Martim, C. C., Almeida, F. T. de, \& Paulino, J. (2013, outubro/dezembro.). Classificação climática e balanço hídrico climatológico no Estado de Mato Grosso. Nativa, Sinop, 1(1), 34 - 43.

Thorthwaite, C. W. (1948). An approach towards a rational classification of climate. Geographical Review, London, 38, 55-94.

Thorthwaite, C. W., \& Mather, J. R. (1955). The water balance (p. 104). New Jersey: Drexel Institute of Technology.

Tres, A. (2016). Classificação climática para o Brasil segundo as zonas de vida de Holdridge. Dissertação de mestrado, Universidade Federal do Paraná, Curitiba. Recuperado de https://acervodigital.ufpr.br/handle/1884/46158

Varejão-Silva, M. A. (2001). Meteorologia e climatologia: versão digital 2. Recife. 